\title{
Change in dust collection efficiency of liquid collectors in conditions of dedusting liquid recirculation
}

\author{
Janusz Krawczyk \\ Cracow University of Technology, Institute of Thermal and Process Engineering, Department of Industrial Equipment, \\ 31-864 Cracow, Jana Pawta II 37, Poland \\ Corresponding author: e-mail: janusz.krawczyk@lsccom.com
}

\begin{abstract}
The high efficiency of industrial wet scrubbers is the result of a simultaneous formation of dust particle collectors. Collectors can be understood as droplets of atomised liquid, bubbles formed in the conditions of intensive barbotage, liquid surface and wet surfaces. All collectors are formed during the operation of a circulating unit. The efficiency of dust collection process also depends on the ability of dust particles to be absorbed by collectors. The study provides an experimental analysis of the effect of the increasing concentration of a dust collection liquid in the conditions of full liquid recirculation on the efficiency of dust collection process in the examined types of collectors.
\end{abstract}

Keywords: dust collectors, dust removal efficiency, wet scrubbers.

\section{INTRODUCTION}

With the full recirculation of the dust collection liquid, during unit operation, the concentration of the suspension formed in the unit will increase. At a certain concentration, specific for the given three-phase gas liquid - solid system, operation difficulties related to the clogging of pipelines transporting the suspension inside the unit or sprinkling elements may occur ${ }^{\mathbf{1}, \mathbf{2}}$. An increased concentration of the suspension may render the liquid distribution in the scrubber difficult and may influence the quality of forming liquid dust collectors ${ }^{3,4}$.

The gradually increasing liquid concentration, may also increase the viscosity of the dust collection liquid and, therefore, obstruct the penetration of dust particles collected on the surface inside the liquid ${ }^{5,6}$.

After reaching a certain concentration threshold, the suspension may lose its Newtonian fluid properties. In these conditions, the apparent viscosity of the suspension, typical for laminar flows, is significantly increased in comparison to the viscosity of the Newtonian suspension. In these conditions, a gradual decline of dust collection efficiency is possible. This effect depends on the physiochemical properties of the dust, kinetic energy of dust particles, but also on the type of the scrubber unit $^{7}$ and, particularly on the contact method between the liquid and gas phases.

The occurrence of operational problems related to the increased concentration of the suspension is obvious. However, the literature on the topic of wet dust collection does not contain information confirming the effect of the suspension concentration on the efficiency of the dust collection process itself. There are also no descriptions of theoretical or experimental studies determining the effect of viscosity and rheological properties of the suspension on the efficiency of the dust collection process 9 .

A method of predicting the particle removal efficiency of gravitational wet scrubbers, that considers diffusion, interception and impaction was presented by Byeon et al. ${ }^{10}$.

Conventional scrubbers are modified to needs of modern industries. For example papers ${ }^{11,12}$ show comprehensive analysis for prediction of dust removal efficiency using twin-fluid atomization in a spray scrubber.
Lim et al. ${ }^{13}$ presented a method of particle removal efficiency prediction of a reverse jet scrubber. Numerical results were compared with experimental and analytic results using average relative velocity in all zones.

Mohan et al. ${ }^{14}$ investigated a pilot plant counter-current spray-column wet scrubber. Experiments were focused on quantification of column efficiency for scrubbing particles from the gaseous waste stream.

Fly-ash removal efficiency in a modified multi-stage bubble column scrubber was examined by Meikap et al. ${ }^{15}$. It has been found that the system had very high efficiency for the scrubbing of fly-ash. In most investigated cases the fly-ash removal efficiency is more than 95\% and in some cases is even $99.5 \%$.

Investigations with nozzle scrubbers were reviewed by Ebert et al. ${ }^{16}$. Different design of scrubbers required different types of nozzles and spray properties to effective performance. All relevant parameters for its operation, e.g. specific water consumption, residence time and specific energy consumption have been investigated in detail. Different pneumatic, atomizing nozzles (with internal and external mixing of phases) in various geometrical parameters were examined.

Gemci and Ebert $^{17}$ reported results obtained from a computer model which describes the removal of fine particles from gas streams in a wet scrubber. The simulation results showed an improvement of the collection efficiency of submicron aerosol particles. The process was explained by the turbulent diffusion mechanism.

Wet scrubbing of polydisperse aerosols by freely falling droplets was examined and described by Park et al. ${ }^{18}$. The study presents analytical solutions for removal of a polydisperse aerosol. The removal mechanisms are explained by Brownian diffusion and inertial impactions.

A method of predicting particle collection efficiency and particle size distribution in a fixed valve tray column was presented by Wang et al. ${ }^{19}$. The particle removal mechanisms consider diffusion, interception, and impaction.

If the concentration of solid particles in dust collection liquid reaches a critical value, over which the efficiency of the process decreases, we can then determine the maximum recirculation degree value - i.e. the recirculation threshold ${ }^{20}$. Discussions confirming the effect of suspension viscosity on the efficiency of the dust collection 
process can be related to the analysis of basic mechanisms affecting particle deposition, particle deposition on liquid collectors collector generating conditions.

All collectors are presented in Figure 1, depicting a circulating scrubber unit ${ }^{7}$. The operation of the unit is similar to typical Roto-Clone Type $\mathrm{N}$ scrubbers $\mathbf{9 , 2 1 , 2 2}$ with one difference - the presented solution does not contain the so-called dirty chamber, moving it to the bottom part of the guide.

Figure 1a presents a diagram of the tested unit and its characteristic cross-section planes. Figure $1 \mathrm{~b}$ shows a schematic representation of dust collectors formed in the guide and the separation space of the unit ${ }^{23}$. The deposition of dust particles from gas occurs as a result of centrifugal forces and secondary circulations in the guide duct as well as the effect of the water curtain, liquid barbotage and the flow of dusty gas through the droplet-splash layer. It is, therefore, obvious that the correct operation of a unit depends on the velocity of the flowing aerosol and the $\mathrm{H}$ liquid level in the unit.

\section{MATERIAL AND METHODS}

In total liquid recirculation in wet dedusting equipment, concentration of solids in a liquid rises. In such conditions, a gradual decrease of their dedusting efficiency is possible. The effect depends on dust physiochemical properties, kinetic energy of particles, the type of equipment used, and specifically on the way contact between liquid and gaseous phases is arranged ${ }^{7}$.

The purpose of the study was to analyse dust retention efficiency change with altered suspension concentration on droplets, in barbotage condition, while particles impact against wet surface as well as free surface of liquid. Tests were carried out on two independent model devices.

The first device consists of three chambers, in which dust separation with changing suspension concentration was analysed independently in droplet area (3), in barbotage conditions (2) as well as on impact against wetted surface (5) (Fig. 1b).

The following test velocities of the dusted gas stream on impact against wet surface were assumed: $20,30,40$ $[\mathrm{m} / \mathrm{s}]$. The velocity interval had a sufficiently large safety margin of potential velocity variations for prospective industry applications of the results.

The gas flow velocity in the drip chamber was 1, 1.5, 2 $[\mathrm{m} / \mathrm{s}]$, and the air outflow rate from the dusted gas inlet piping, at the liquid surface in the barbotage surface was $9,12,15[\mathrm{~m} / \mathrm{s}]$, respectively.

For the research, titanium dioxide dust was selected, in a very fine-grained, yet very well wettable dust form ${ }^{24}$.

The wettable dust delivered at the liquid surface was absorbed instantaneously, thus enabling its subsequent impact on the surface. Titanium dioxide used for the research, according to its manufacturer and laboratory measurements, conducted with a method used elsewhe$\mathrm{re}^{\mathbf{2 5}}$, consisted of particles less than $10[\mu \mathrm{m}]$ in size.

\section{Multi-chamber wet deduster for estimation of dedusting efficiency on droplets, in barbotage area and during impact against a wet surface}

In Figure 2, an experimental set-up diagram is shown. On the inlet piping, a pneumatic classifier (1) was installed, separating potential dust agglomerates larger than $20[\mu \mathrm{m}]$ in size. The aerosol was generated by introducing dust into the inlet piping through a dispenser (10). The dusted gas was directed to a wet-type dedusting system (15) for a thorough clean-up, and was subsequently removed from the station through a drop separator (8) and outflow piping.

In vertical segments of inlet and outflow pipes, similar systems were installed to measure dust concentration / $\mathrm{S}_{\mathrm{w}}$ and $\mathrm{S}_{\mathrm{o}} /$, fraction composition $/ \mathrm{I}_{\mathrm{w}} \mathrm{i} \mathrm{I}_{\mathrm{o}} /$, gas humidity / a)

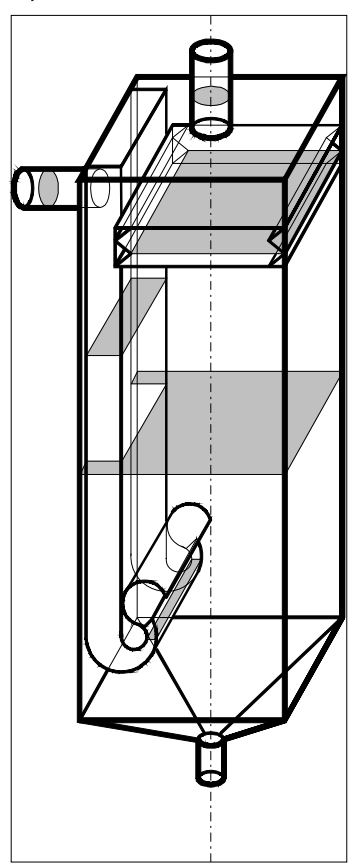

b)

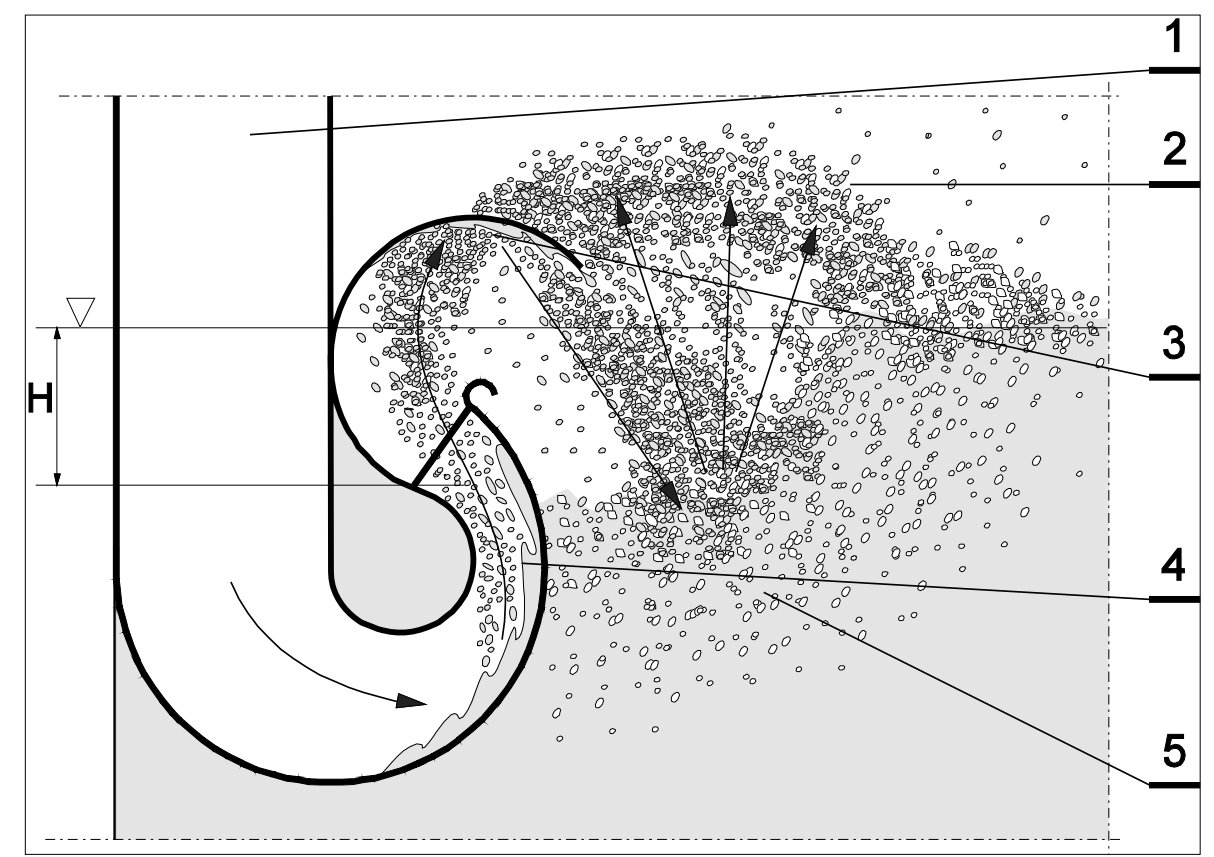

Figure 1. Experimental unit and dust collection mechanism. 1a - diagram of the tested unit, $1 \mathrm{~b}$ - formation of dust collectors, 1 - guide duct, 2 - droplet and splash layer, 3 - formation of the water curtain, 4 - water film in the guide, 5 - aerosol penetration into the liquid, $\mathrm{H}-$ fill level 
1. Cyclone sparator

2. Cyclone,

3. Measuring systems, $S$ - concentration, I- fraction composition, $\varphi$ - humidity,

4. Pressure / temperature recorder.

5. Dust separation - drip chamber.

6. Dust separation - barbotage chamber,

7. Dust separation - surface impact chamber,

8. Drop separator,
9. Fan,

10. Dust dispenser,

11. Gas distribution collector

12. Wet surface,

13. Tank,

14. Liquid inlet pipings,

15. Rotary apparatus.

15. Rotary apparatus,
16. Measuring orifice.

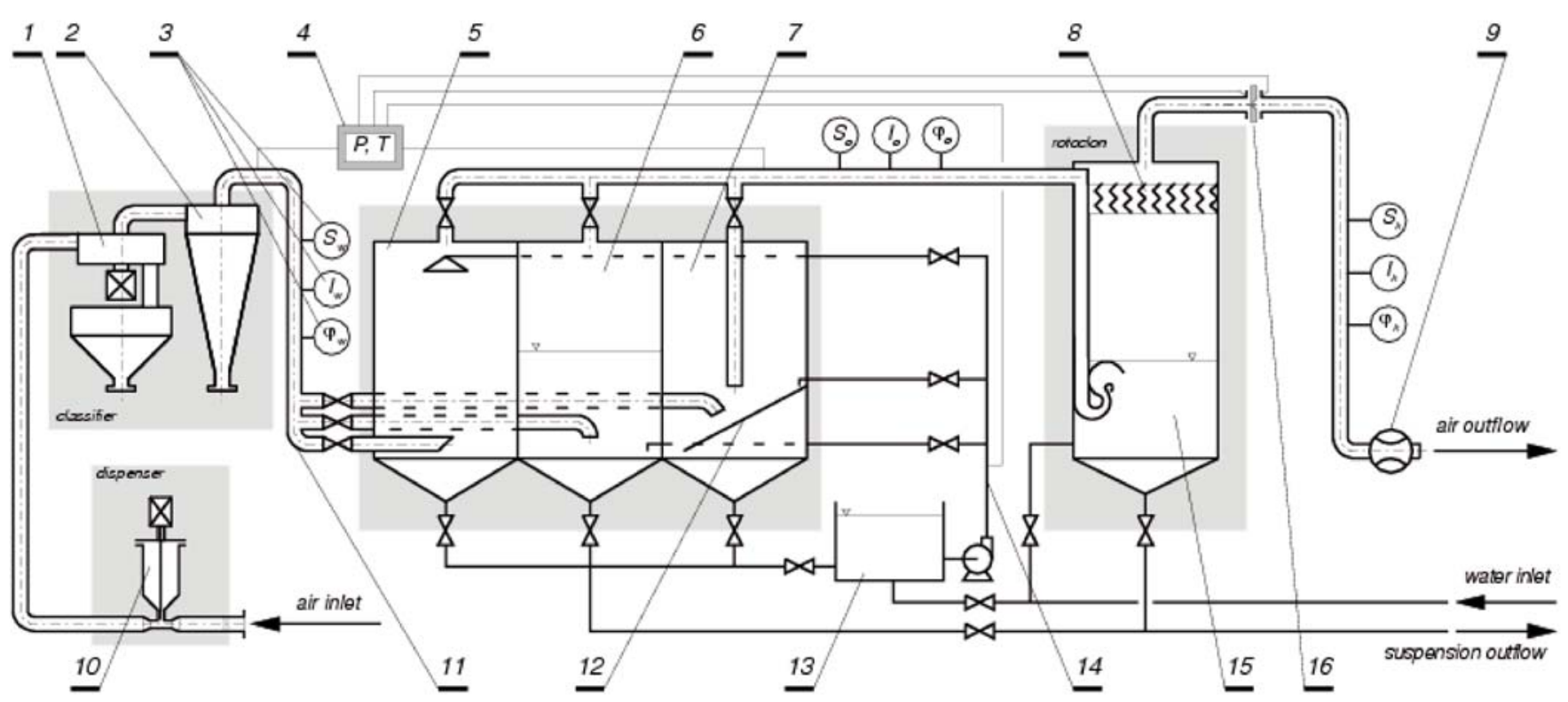

Figure 2. Experimental set-up diagram

$\varphi_{\mathrm{w}}$ i $\varphi_{0} /$, temperature, gas volumetric flux and hydraulic flow resistance.

To evaluate fractional efficiency, multi-stage cascade impactors were used, enabling direct in-piping measurement, thus avoiding the necessity to preliminarily separate a specific dust volume designated for measurement purposes.

\section{Aerosol-to-liquid impact chamber for dedusting efficiency evaluation}

A significant part of the second test stand was the dedusting chamber, enabling crossflow of a suspension in relation to the dusted gas impacting against the liquid surface. At the stand, a number of general efficiency tests were carried out in changing conditions of the dusted air outflow impacting against the liquid surface, with constant dust dispensing into the system. Dedusting efficiency was evaluated by measuring the mass of dust delivered to the system versus dust retained by the filter at the outflow piping. A diagram of the test stand was presented in Figure 3.

In the diagram, the collector (3) is shown, its purpose is to deliver an aerosol into the chamber and piping collectors (6) and (9), enabling crossflow of the liquid and the supplied aerosol. At the height of $15 \mathrm{~mm}$ from the chamber base surface, inlet and outflow channels were milled in the form of $5 \mathrm{~mm}$ wide slots. With pipes attached, they served as inlet and outflow collectors. Thus, constant liquid crossflow through the chamber was enabled in relation to the aerosol direction.

A sample collection point (10) was used to control suspension concentration changes over time.

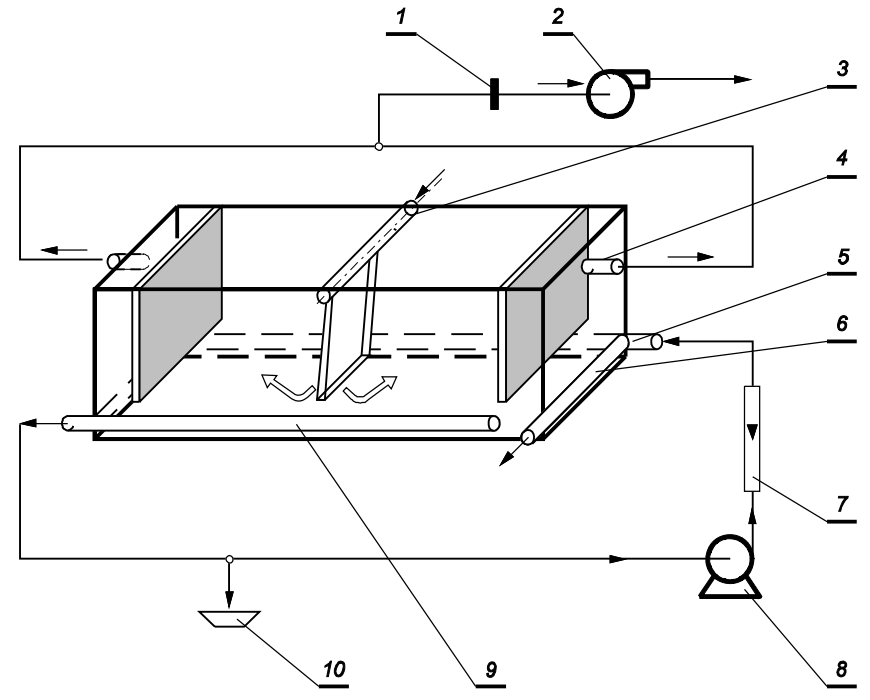

Figure 3. Schematic diagram of the gas-to-liquid impact scrubbing test stand. 1 - measuring orifice, 2 - fan, 3 - aerosol supply nozzle, 4 - aerosol outlet, 5 - suspension supply piping, 6 - backup suspension outflow piping, 7 - rotameter, 8 - pump, 9 - suspension outflow piping, 10 - suspension sample collection

\section{RESULTS AND DISCUSSION}

\section{Results obtained from multi-chamber device}

Sample results of fractional dedusting efficiency tests are presented in Figures 4 and 5.

The efficiency of titanium dioxide dedusting in water was tested for specific liquid collectors, dominant in each chamber of the device. The test stand enabled evaluation of influence of collectors on dedusting efficiency, for different levels of dust suspension concentration in water. 
Assuming that in each chamber of the test stand, the dominant role is played by just one collector, tests were carried out for the case of barbotage ${ }^{23}, 26$, 27, dust retention by the water spray ${ }^{28}$, as well as particle retention on the wetted surface ${ }^{26-29}$. It should be noted, that in the intensive barbotage chamber with high dusted gas velocity a droplet layer emerges, supporting the dedusting effect. It can be assumed that contribution of other supporting collectors is minimal, therefore general dedusting efficiency is reached by basic collectors only.

Figure 4 shows test results of the fractional efficiency of water-assisted titanium dioxide dedusting for three collectors. According to the graph, peak efficiency was achieved in barbotage. It was to be expected since for gas cavity collectors, due to extended and constantly regenerating interface, a very intensive dust particle retention process occurs.

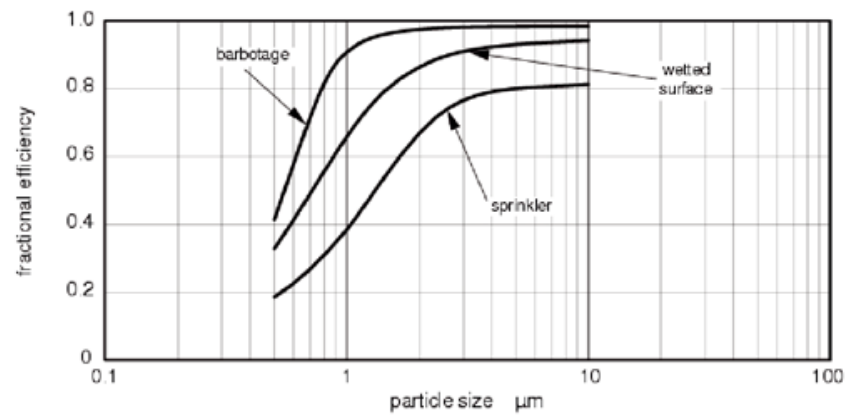

Figure 4. Fractional efficiency of titanium dioxide dedusting in pure water

For the two remaining collectors, significantly lower dedusting efficiency levels were obtained during the test. Compared to approximately $90 \%$ efficiency in barbotage, the dedusting efficiency of the sprinkler fell down to $70 \%$.

In Figure 5 test results are presented, showing the fractional efficiency of titanium dioxide dedusting with suspension in maximum concentration used for testing.

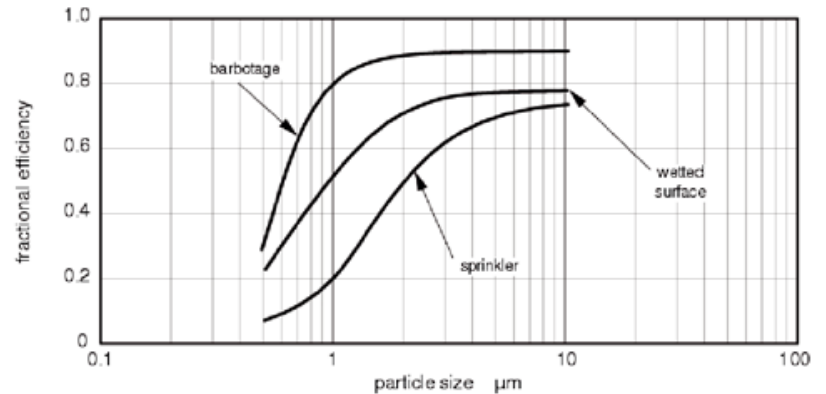

Figure 5. Fractional efficiency of titanium dioxide dedusting in suspension

As shown in the graphs, for all the generated liquid collectors, dedusting fractional efficiency with suspension in maximum concentration used for testing, i.e. $28 \%$ of the mass, was lower than that of pure water.

Results of investigations of general efficiency in the impact chamber

Sample test results for instantaneous and cumulative efficiency calculations for two aerosol flow velocities are presented in Figure 6 and Figure 7.

In Figure 6, a sample dependency of cumulative efficiency on deposited mass is presented, for titanium
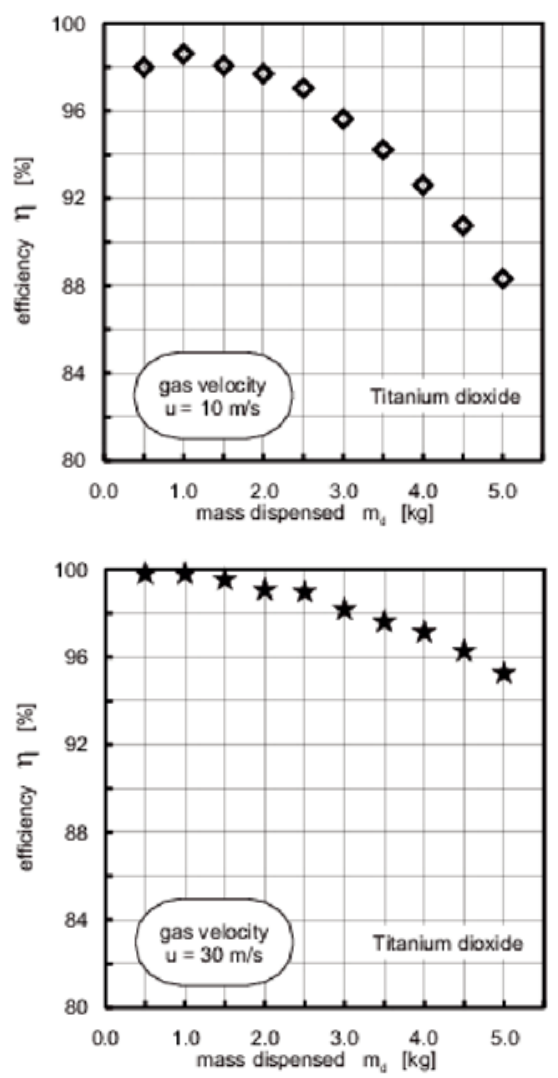

Figure 6. Dependency of cumulative efficiency on deposited mass, for titanium dioxide
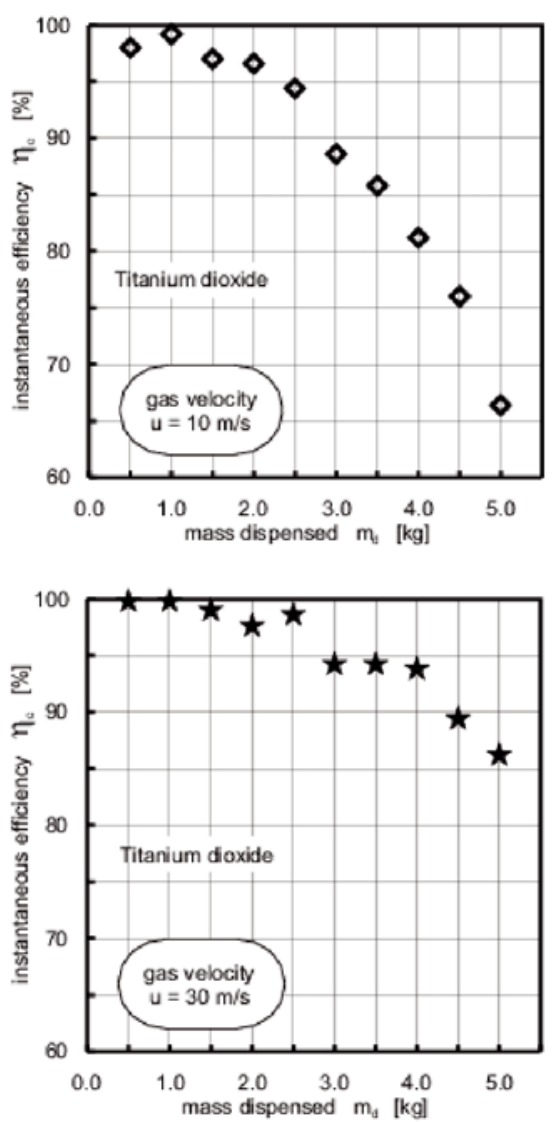

Figure 7. Dependency of temporary efficiency on deposited mass, for titanium dioxide

dioxide. In almost all the graphs, for different velocities of the dusted air flowing out of the nozzle, the initial operating range does not exhibit any suspension absorption capacity changes over time. Beyond the range, 
efficiency tends to drop, albeit not abruptly. Therefore, evaluation of a specific concentration limit, above which the efficiency becomes significantly degraded, becomes problematic.

In Figure 7, dependency of temporary efficiency on deposited mass for titanium dioxide is shown. The distribution of test points reflects the rising inaccuracy of measurements, nonetheless it confirms the hypothesis of changes in suspension absorption capacity.

\section{Mathematical model of particles dedusting on the liquid surface}

A mathematical model for both discussed cases may be derived from the following relationships ${ }^{30}$ :

$\dot{m}_{z}=\dot{m}_{d}-\dot{m}_{w}$

where:

$\dot{m}_{z}$ - change in mass of retained dust in time, change in sediment mass in time,

$\dot{m}_{d}$ - change in mass of inflowing (supply) dust in time, change in mass of deposited particles,

$\dot{m}_{w}$ - change in mass of generated dust emission, removed from the sediment.

The mathematical model of changes in mass of dust retained in the suspension (Fig. 8), takes the following form:

$m_{z}=A \cdot u^{D}\left[1-\exp \left(-B \cdot u^{2-C} \cdot m_{d}\right)\right]$

where:

$m_{d}$ - cumulative mass of supplied dust, directly proportional to the time of operation.

Values of regression coefficients for model (2) and relative errors were calculated using an estimation method described and used, e.g. in ${ }^{31-33}$ :

$\mathrm{A}=91.780, \mathrm{~B}=0.010, \mathrm{C}=2.000, \mathrm{D}=0.020$

The average correlation match relative error is $2.55 \%$.

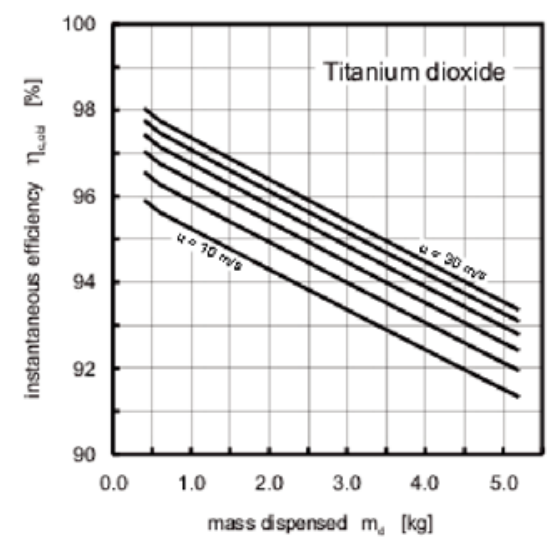

The effect of degraded fractional dedusting efficiency pertains to both small dust particles, several microns in diameter, and to those resulting from fraction decomposition of dust used for testing. This shows that some dust was not retained by the suspension.

The use of a physical model taking into account changes of the absorption capacity of a suspension with its concentration may partially explain test results. Impacting dust particles are not absorbed by the suspension, as they bounce off dust particles previously retained in it, and are therefore not absorbed into the liquid. It can be assumed, that in such conditions dust particles of small kinetic energy may bounce off particles already retained on the liquid collector surfaces. At high concentrations, particle chaining occurs in suspension, enabling easy deflection of low energy particles. The particle features sufficient energy to enter the suspension, destroy the emerging structures and overcome the resistance of the medium.

The above may partially explain a change of dedusting efficiency with a rising concentration of the suspension, as well as the dependency of efficiency on the growth of kinetic energy of dust particles, relative to increase of aerosol flow velocity.

It should be emphasised that with increase of dedusting suspension concentration, conditions of collector generation change, which affects dust particle retention.

It is specifically evident in intensive barbotage, when aerosol cavities penetrating the high concentration suspension layer are irregular both in shape and outflow frequency.

With a rising suspension concentration, mist uniformity and the shape of emerging droplets dispersed by the sprinkler is also altered.

Higher kinetic energy of the high concentration fluid flow allows for more efficient dispersion of the layer

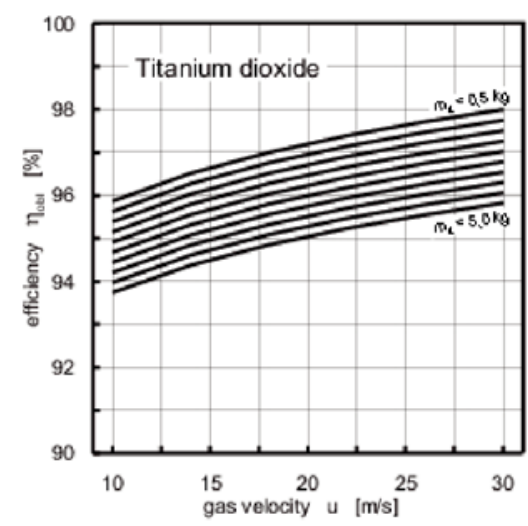

Figure 8. Graphs based on obtained correlation for titanium dioxide

\section{CONCLUSIONS}

Having compared the test results of fractional dedusting efficiency of titanium dioxide for all the liquid collectors used in the tests, a conclusion can be drawn that suspension concentration significantly affected the resulting dedusting efficiency.

The cumulative curve of fractional dedusting efficiency for the maximum suspension concentration used in the tests falls below the pure water curve. wetting the surface, exposing it entirely for subsequent impacts and disabling dust particle retention.

As the above effects superimpose, the final result is degradation of both general and fractional dedusting efficiency levels. This pertains to cases of dust particle retention by the water spray generated by the sprinkler, in the barbotage chamber, as well as on impact of the dusted gas against the wetted surface and liquid surface. 
The analysis of general dedusting efficiency of titanium dioxide for the collectors considered in the current paper demonstrates that the highest efficiency was achieved in intensive barbotage conditions.

The analysis of efficiency changes in barbotage conditions shows that the effect of dedusting efficiency degradation grows with increasing gas flux, which is consistent with the physical model used in the study.

\section{NOMENCLATURE}

\begin{tabular}{|c|c|}
\hline & - regression coefficient of th \\
\hline$I_{w}, I_{\mathrm{o}}$ & $\begin{array}{l}\text { - fraction composition (at the inlet and } \\
\text { at the outlet), [-] }\end{array}$ \\
\hline$m_{z}$ & - mass of retained dust, $[\mathrm{kg}]$ \\
\hline$m_{d}$ & - mass of dust input to the system, $[\mathrm{kg}]$ \\
\hline$m_{z}$ & $\begin{array}{l}\text { - change in time of retained particulate } \\
\text { mass, }\left[\mathrm{kgs}^{-1}\right]\end{array}$ \\
\hline$\dot{m}_{d}$ & $\begin{array}{l}\text { - change in time of input particulate } \\
\text { mass, }\left[\mathrm{kgs}^{-1}\right]\end{array}$ \\
\hline$\dot{m}_{w}$ & $\begin{array}{l}\text { - change in time of particulate emission, } \\
{\left[\mathrm{kgs}^{-1}\right]}\end{array}$ \\
\hline$m_{z}^{*}$ & $\begin{array}{l}\text { - asymptotic value of particulate (dust) } \\
\text { mass, }\left[\mathrm{kgs}^{-1}\right]\end{array}$ \\
\hline$S_{w}, S_{\mathrm{o}}$ & $\begin{array}{l}\text { - dust concentration (at the inlet and at the } \\
\text { outlet), }\left[\mathrm{kgm}^{-3}\right]\end{array}$ \\
\hline$t, \tau$ & - time $s,[s]$ \\
\hline$u$ & - linear velocity, $\left[\mathrm{ms}^{-1}\right]$ \\
\hline$c$ & $\begin{array}{l}\text { - mass of solid particles in the suspension, } \\
{\left[\mathrm{kgkg}^{-1}\right]}\end{array}$ \\
\hline$j_{w}, j_{\mathrm{o}}$ & $\begin{array}{l}\text { - gas humidity (at the inlet and at the } \\
\text { outlet), [\%] }\end{array}$ \\
\hline$\eta$ & $\begin{array}{l}\text { - cumulative or instantaneous dedusting } \\
\text { efficiency, [\%] }\end{array}$ \\
\hline
\end{tabular}

\section{LITERATURE CITED}

1. Łopata, S. \& Ocłoń, P. (2012). Modelling and optimizing operating conditions of heat exchanger with finned elliptical tubes. In L. Hector Juarez (Ed.), Fluid dynamics, computational modeling and applications (pp. 327-356). Rijeka, Croatia: InTech.

2. Ocłoń, P., Łopata, St., Nowak, M. \& Benim, A. (2014). Numerical study on the effect of inner tube fouling on the thermal performance of high-temperature fin-and-tube heat exchanger. Prog. Comput. Fluid Dyn. 15(5), 290. DOI: 10.1504/ PCFD.2015.072014.

3. Brauer, H., Dyląg, M. \& Talaga, J. (1989). Zur fluiddynamik von gerührten gas/feststoff/fltssigkeits-systemen. Chem. Ing. Tech. 61, 978-979 (in German).

4. Brauer, H., Dylag, M. \& Talaga, J. (1996). Modellvorstellung zur entstehung der vollständigen suspension im rühbehälter. Forsch. Ingenieurwes 62, 239-245 (in German).

5. Dyląg, M. \& Talaga, J. (1995). Modeling of multiphase flows. Chem. Process Eng. 16(3), 407-420.

6. Kabsch, M. (1976). Methods of dust wettability measurements. Wrocław, Poland: Wroclaw University of Technology Publisher (in Polish).

7. Nazarow, G., Krawczyk J., Blinicziew, W., Czagin, O. (2000). Influence of the design of the dust collecting apparatus on the limiting concentration of the irrigating suspension. Himia Himic. Tehnol. 43(2), 80-85 (in Russian).

8. Krawczyk, J. (2015). Development of wet methods of industrial gasses dedustind on the basis of experimental investigations. Cracow, Poland: Cacow University of Technology Publisher (in Polish).
9. Krawczyk J., Dyląg, M. \& Rosiński, J. (1998). Verminderung des wasserverbrauchs bei der entstaubung. Gefahrst. Reinhalt. L. 59(1), 45-49.

10. Byeon, S.H., Lee, B.K. \& Mohan, B.R. (2012). Removal of ammonia and particulate matter using a modified turbulent wet scrubbing system. Sep. Purif. Technol. 98, 221-229. DOI: 10.1016/j.seppur.2012.07.014.

11. Mohan, Jain, R. \& Meikap, B. (2008). Comprehensive analysis for prediction of dust removal efficiency using twin-fluid atomization in a spray scrubber. Sep. Purif. Technol. 63 (2), 269-277. DOI: 10.1016/j.seppur.2008.05.006.

12. Kim, H., Jung, C., Oh, S. \& Lee K. (2001). Particle removal efficiency of gravitational wet scrubber considering diffusion, interception and impaction. Environ. Eng. Sci. 18 (2), 125-136. DOI: 10.1089/10928750151132357.

13. Lim, K., Lee, S. \& Park, H. (2006). Prediction for particle removal efficiency of a reverse jet scrubber. J. Aerosol. Sci. 37 (12), 1826-1839. DOI: 10.1016/j.jaerosci.2006.06.010.

14. Mohan, B., Biswas, S. \& Meikap, B. (2008). Performance characteristics of the particulates scrubbing in a counter-current spray-column. Sep. Purif. Technol. 61(1), 96-102. DOI: 10.1016/j.seppur.2007.09.018.

15. Meikap, B. \& Biswas, M. (2004). Fly-ash removal efficiency in a modified multi-stage bubble column scrubber. Sep. Purif. Technol. 36(3), 177-190. DOI: 10.1016/S1383-5866(03)00213-2.

16. Ebert, F. \& Büttner, H. (1996). Recent investigations with nozzle scrubbers. Powder Technol. 86(1), 31-36. DOI: 10.1016/0032-5910(95)03034-4.

17. Gemci, T. \& Ebert, F. (1992). Prediction of the particle capture efficiency based on the combined mechanisms (turbulent diffusion, inertial impaction, interception, and gravitation) by a 3-D simulation of a wet scrubber. J. Aerosol. Sci. 23, 769-772. DOI: 10.1016/0021-8502(92)90525-Z.

18. Park, S., Jung, C., Jung, K., Lee, B. \& Lee, K. (2005). Wet scrubbing of polydisperse aerosols by freely falling droplets. $J$. Aerosol. Sci. 36, 1444-1458. DOI: 10.1016/j.jaerosci.2005.03.012.

19. Wang, Q., Chen, X. \& Gong, X. (2013). The particle removing characteristics in a fixed valve tray column. Ind. Eng. Chem. Res. 52(9), 3441-3452. DOI: 10.1021/ie3027422.

20. Krawczyk, J. (1996). Wet dedusting, heat and mass exchange in apparatuses of intense performance. Moscow, Russia: Russian National Academy Publisher.

21. Talaga, J., Brauer, H. \& Dyląg, M. (1996). Modellvorstellung zur entstehung der vollständigen suspension im rühbehälter. Forsch. Ingenieurwes 62(9), 239-246. DOI: 10.1007/ BF02601430.

22. Löffler, F. (1988). Staubabscheiden. New York, USA: Georg Thieme Verlag.

23. Krawczyk, J., Czagin, O. \& Postnikowa, I. (2010). The change of fractional dedusting efficiency with increase of liquid concentration for different wettability dusts. In proceedings of IX International Conference "Theoretical Basics of Energy and Resource-saving Processes, Equipment and Environmentally Safe Industries", 28-30 September 2010 (pp. 121-128). Ivanovo, Russia: Ivanovo Stte University of Chemistry and Technology Publisher (in Polish).

24. Krawczyk, J. \& Pikoń, J. (1986). Abscheider mit zellenftllkorpern. Staub. Reinhalt. Luft 1, 22-25 (in German).

25. Dłuska, E., Hubacz, R., Wroński, S., Kamieński, J., Dyląg, M. \& Wójtowicz, R. (2007). The influence of helical flow on water fuel emulsion preparation. Chem. Eng. Commun. 194 (10), 1271-1286. DOI: 10.1080/00986440701293959.

26. Krawczyk, J., Roszak, Z. \& Wisła H. (2006) Dedusting in bubbling and drop zones of periodic apparatus. Chem. Enginee. Equip. 45(37), 99-101 (in Polish).

27. Wisła, H. (2009). Wet dedusting for full liquid recirculation. Doctoral dissertation, Cracow University of Technology, Cracow, Poland (in Polish).

28. Krawczyk, J., Maszek, L., Mieszkowski, A. \& Roszak, Z. (2008). Wet dust extraction in the condition of total liquid 
recirculation. Czasopismo Techniczne - Technical Transactions 2-M/2008 (2), 143-154 (in Polish).

29. Krawczyk, J., Czagin, O. \& Postnikowa, I. (2012). Changes in the dust capture during the impact aerosol of the liquid surface. Czasopismo Techniczne - Technical Transactions 2-M/2012 (6), 207-214 (in Polish).

30. Szatko, W., Blinicziew, W. \& Krawczyk, J. (2011). Comparison of mathematical models describing changes of the suspension absorption capacity and thermal resistance of the sludge. In G. Wozny \& Ł. Hady (Eds.), Process Engineering and Chemical Plant Design 2011, (pp. 103-113). Berlin: Universitätsverlag der TU Berlin.

31. Wójtowicz, R., Lipin, A.A. \& Talaga, J. (2014). On the possibility of using of different turbulence models for modeling flow hydrodynamics and power consumption in mixing vessels with turbine impellers. Theor. Found. Chem. Eng. 48 (4), 360-375. DOI: 10.1134/S0040579514020146.

32. Kamieński, J. \& Wójtowicz, R. (2001). Drop size during dispersion of two immiscible liquids in a vibromixer. Chem. Process Eng. 22(3C), 597-602 (in Polish).

33. Wójtowicz, R. (2014). Choice of an optimal agitated vessel for the drawdown of floating solids. Ind. Eng. Chem. Res. 53 (36), 13989-14001. DOI: 10.1021/ie500604q, 53 13989-14001. 